\title{
Introduction: The self within the space-time of language performance
}

Theory \& Psychology 20I4, Vol. 24(4) 433-44I (C) The Author(s) 2014

Reprints and permissions: sagepub.co.uk/journalsPermissions.nav DOI: 10.1 | 177/09593543|4532035

tap.sagepub.com

\section{Marie-Cécile Bertau}

Ludwig Maximilian University of Munich

\begin{abstract}
Scientific research in a dialogical paradigm highlights processes and insists on human beings' relatedness. The basic move is thus a shift from the self-contained "l" to the related self, where the other is seen as the self's pre-condition. This must be accompanied by a similar shift with regard to language: language has to be viewed as a genuinely dialogical and plural phenomenon. Through five target articles and four commentaries addressing themes across the articles, this special issue takes a close look at the relationship between language and the self and explores some of the topics surfacing within the dialogical perspective: the "in-between" of the related subjects; movements, such as in speaking, listening, thinking, and writing, as an inherent part of the dynamics of the selves' relatedness. As a result, language gets a rhetorical, phenomenal volume, and the subject is conceived as a self by virtue of its language performances.
\end{abstract}

\section{Keywords}

dialogic paradigm, language activity, listening, self, thinking, time, writing

For about two decades, a dialogical paradigm has been worked out in psychology and linguistics (e.g., Bertau, 2011a, 2011b; Bertau, Gonçalves, \& Raggatt, 2012; Hermans \& Gieser, 2012; Linell, 2009; Valsiner, 2007; Weigand, 2009). This paradigm is itself reminiscent of earlier related understandings of human beings, each of which gives priority to processes rather than fixed products. Such processes can be social, dialogical, rhetorical, or psychological. I think here of the works of, for instance, Mikhail Bakhtin, Valentin Vološinov, William James, George H. Mead, James M. Baldwin, Helmuth Plessner, Ludwig Feuerbach, Wilhelm von Humboldt, and Giambattista Vico. Further,

\section{Corresponding author:}

Marie-Cécile Bertau, Ludwig-Maximilians-Universität München, Institute for Phonetics and Speech Processing, Schellingstrasse 3, 80799, München, Germany.

Email: bertau@Imu.de 
the perspective on dialogical processes entails a clear acknowledgment of the sociality of human beings: human beings are fundamentally social, their sociality is the very condition of their individuality. The social and the individual then stand precisely not in contradiction or opposition to each other, rather, they are dynamically related, generating each other. This leads to an insistence on human beings' relatedness to their specific social, historical, and cultural environment, as well as to their "consociates"- the individuals a person lives and ages with (Schütz, 1967). In fact, scholars in the dialogical paradigm often themselves refer to at least one of the aforementioned thinkers. In addition to that rich tradition, the dialogical paradigm clearly links to contemporary frameworks interested in forms of cooperation and coordination between individuals, focusing on, for instance, intersubjectivity (e.g., Trevarthen, 1999; Trevarthen \& Aitken, 2001) and joint actions (e.g., Clark, 1996; Gergen, 2009), or addressing social cognition in a resolutely interactive understanding (e.g., De Jaegher \& Di Paolo, 2007; De Jaegher, Di Paolo, \& Gallagher, 2010).

Viewed in a broader frame, scientific research driven by the concept of dialogicality stands in opposition to an individualistic ideology of human beings, stating, in short, that the study of the isolated mind, cognitive abilities, or individual brain, reveals how human beings develop, acquire language, communicate with others, process information, possess a self and an identity, and think. Hence, dialogical research rejects an individualistic methodology (see e.g., Gallagher, 2012; Shotter, 1993). Asserting the relatedness of human beings to their consociates, to themselves, and to their specific historical and socio-cultural environment, we get a picture of humans where otherness plays a central role. The basic move needed in constructing an alternative to individualistic methodology is thus a shift from the self-contained I to the related self, where the other is seen as the self's pre-condition-to acquire, develop, and perform language, thinking, consciousness, as well as its self.

But this move seems incomplete if it is not accompanied by a similar shift with regard to language. A scientific paradigm that aims at de-centering and disempowering the selfcontained I, that dynamizes and pluralizes the self, cannot rest upon a notion of language which utilizes a transmission model of language, that precisely underscores each individual's self-containment and the pure instrumentality of language: a controllable tool for its master's use. Hence, a notion of the individual based in dialogicality and relatedness has to be complemented by a notion of language similarly grounded in dialogicality, highlighting the self's relatedness. This means abandoning the primacy of language over speech, rejecting essentialist assumptions together with an instrumental view of language (e.g., Gadamer, 1986). It also means focusing on the performance of language: an activity experienced and undertaken by other-related selves, a symbolic as well as sensorial activity (Gratier \& Bertau, 2012). Following this move, one comes to consider language beyond its tool-like quality, taking its quality as a medium, in the sense of an enabling element, into account. Moreover, the other-relatedness of the self indeed necessitates a medium, and that medium cannot be conceived in terms of code transmission if it is to relate self and other beyond mere technical connectedness. In my view, a notion of language is needed that addresses it as a positioning, evaluating, and mediational process. Language mediates self to other and to their common reality; in this, it has a formative power well beyond "information transmission." It is a medium abundant with 
individual and community meanings which are in intense dialogic relations any time one speaks to another (be this other actually or imaginatively present). It is not a transparent medium, something we could just look through to see "the self" or "thinking"- disregarding language and viewing it only as the vestment to something "proper." In fact, it is in the specific forms of language as performed by situated self-other related individuals that we can observe the self, thinking, and consciousness. Two basic ideas come here together: first, Wittgenstein's urge to look at the phenomenon in question instead of thinking of something "behind" the phenomenon $(1953, \S 66)$ — what is to be understood is there, not hidden, although seemingly hidden because of its "simplicity and familiarity" making one "unable to notice something because it is always before one's eyes" (1953, §129). Second, following Gadamer (1986), there is no standpoint outside the medium of language. This "within-the-phenomenon position" as living human beings as well as investigators of our own human being-ness is worthy of note. It is, in my view, a challenge and an outstanding possibility to gain access to scientific knowledge.

Hence, a dialogical paradigm for the human sciences leads to a different notion of the subject as well as of language. Looking more closely at language from the perspective of an other-related, dialogical self, leads one to consequently explore the relation itself, its formation and functioning via language as the medium of human beings qua mediated beings. It seems to me that language as medium and means for the dialogical self (Bertau, 2011a, 2011b) is under-represented in dialogical self theory. This assessment also holds for psychological work in the cultural-historical tradition, which tends to overemphasize "semiotic mediation" viewed in a tool-oriented perspective. ${ }^{1}$ As a result, language is either a "transparent medium" enabling a look at the "self proper," or an instrument the socio-cultural subject uses in his/her activities. In addition, from a communicative point of view, language is still conceived as operating between some clearly distinguished speaker and listener. This treatment of separable communicative roles is undergirded by an implicit Cartesian, that is, a monological view of the speaker: the speaker is the one with authority on his/her meanings in using language in order to render his/her intentions by accurately coded messages to be accurately decoded as well.

Clearly, a challenge results from these considerations. If core entities such as the subject, language, and consciousness are conceived through time-bound, dialogical, and relational processes, the "doing-of" language, of the self and of consciousness must be theorized and empirically made accessible by adequate methodologies. This "doing-of" foregrounds not only processes and time and their necessary connection, but also the locus of its happening as an "in-between" pertaining to living beings. This in-between is the interaction, the cooperation, or the language activity as autonomous event of specific quality and with specific effects: affecting the protagonists beyond their individual control and intentions. The in-between as a space bridging subjects is already a topic, in the phenomenological philosophy of Merleau-Ponty (1968), and it belongs of course to the philosophy of Vološinov (1929/1986) and Bakhtin (1929/1984; 1986), as Shotter and Billig (1998) highlight. Indeed, acknowledging that locus, which I address as "spacetime," leads to a wealth of questions that open up new perspectives, challenging our usual (e.g., dichotomic, reifying, separating) patterns of thought. Thus, facing the dialogical paradigm we must ourselves learn to think with it - still. Positioning ourselves within that paradigm does not automatically resolve the problem of methodological 
individualism, rather, it is the beginning of the questioning itself. Shotter and Billig wrote in 1998: "but the few issues we have so far mentioned are just the beginning of the uncanny and extraordinary consequences of recognizing the dialogical nature of the interwoven flow of the living, responsive, relational, language-activity between us" ( $p$. 26). Specifically with regard to the in-between, I hold that the beginning mentioned by Shotter and Billig is still happening. In saying this, I think of a crucial point (Bertau, 2011a, 2011b): language is not something that is put to use and then happening between selves, or, put more generally: the in-between is not something emerging from the activities of the subjects - it is rather an "enabling element" prior to relations and in this sense a medium that generates the subjects as subjects, that is, as related, dialogical selves. ${ }^{2}$

This special issue proposes a close and, as much as possible, a precise, curious, and investigative look at the specific relationship between language and the self. It links explicitly language and the self in a non-individualistic perspective, and explores some of the topics coming up within that perspective. As was already pointed out, the "inbetween" of the related subjects together with the dimensions of space and time of the dialogical performance is a core topic. Movements come to the fore as inherently part of the dynamics of the selves' relatedness: movements in speaking, thinking, and writing, for instance. Movements where we can witness "the work of language" for thought (Humboldt), for the self, and for consciousness (Vygotsky). Movements signifying the self's very activity, be it between actual selves, or between imagined, simulated positions and voices of a self on its own. I think that this link enriches both core notions: language gets a rhetorical, "phenomenal volume," and the subject becomes a self by virtue of language as medium: its listening, speaking, thinking, writing, and reading are public performances making up its uniqueness as well as its sociality.

The present issue results from two symposia and several dialogues that took place at the 7th International Conference on Dialogical Self in Athens, Georgia, USA, October 25-28, 2012. These symposia were conceived in mutual relationship, echoing each other through their topics addressing "language and the self," as well as "time and communication." In this way, I tried to build intertextual and inter-situational links that could enhance each single contribution. This intertextuality was continued and deepened by the audience, colleagues who often attended both symposia. The contributions to the present issue take up these vivid conversations from Athens, bringing together the talks as well as those dialogic partners willing to go further into discussion with the ideas presented via written commentary. Hence, the present issue first proposes five contributions on the basis of the conference talks and these are followed by four commentaries. In order to keep as much as possible to intertextuality and dialogicality, I asked the commentators not to comment on any single article in detail, but rather to choose core themes across several articles. This should give space to the commentator's own lines of thinking and research, opening up to different ideas and connections.

The opening contribution (Bertau, 2014a) asks how language functions as symbolic means and what this fulfills for the dialogical self. The specificity of language functioning is described by Bühler's (1934/2011) term of displacement. Expanding Bühler's notion into symbolic displacement a specific movement appears, that language invites the communicating selves to follow together. By following this movement induced by language, the partners come to experience a common affective-cognitive reality that is 
otherwise not accessible - that is, un-sayable and unthinkable. Addressing thinking from a rhetorical and dialogical perspective, Antonia Larrain and Andrés Haye (2014) propose an alternative to the representationalist notion of concepts. In order to build that alternative, the authors turn to William James' and Lev Vygotsky's theorizings, coming to an understanding of concepts as processes that unfold through speech according to social dynamics. As a result, Larrain and Haye propose to conceive concepts as generic generalization processes that unfold through discourse in response to others' generalizations. Andrea Karsten's (2014) contribution continues the topic of dialogical thinking by investigating the dynamics of inner speech during writing. Karsten inquires into the functionality of these dynamics for the writing process with the aim of tracing dialogic movements between different modes of utterances (spoken, written, or inner utterances). Karsten presents three case studies, building on the auto-confrontation method (Clot, 2005), a highly interesting methodology from a dialogical-psychological point of view. Inner speech is shown to be crucial for writing; its functionality is manifold. The method apparently makes visible precisely the "dialogic volume" of language activity. Hence, Karsten's application of this method is innovative and inspiring, calling for further methodological discussions within the non-individualistic paradigm.

Lisbeth Lipari's (2014) contribution turns to the way dialogical interaction itself is conceived. Our attention is turned to the fact that, for the most part, our underlying models of dialogic interaction tend to depict dialogue as a sequential exchange between individual subjects that moves back and forth in a linear sequence. Hence, dialogic models tend to rely upon spatialized metaphors, translating time into space, moments into circumscribed places. Lipari urges an opening up of spatiality and therefore proposes an alternative model of dialogic interaction. To this end, intersubjectivity is recast from a spatialized between generated by individual subjects to what she calls "interlistening," wherein speaking, listening, and thinking come to co-occur in a dense movement. Consistently following the idea of language as process and activity, Marie-Cécile Bertau (2014b) proposes a theorization of language as medium, understood as an "enabling element." The notion of medium leads in turn to "the middle," or the "in-between." Relationships are constituted by that in-between, and subjects are related by virtue of that in-between, forming their relatedness to each other. The question is then, how the medium functions, how it supplies language forms as possibilities of dialogically related subjectifications in language. Time, again, is assumed to be a key notion to this questioning.

These target articles are followed by rich commentaries from four colleagues who address several notions, arguments, and understandings across the articles, developing and also contradicting them by their own approaches and traditions, complementing and differentiating the topics broached. In so doing, the issue's topic - the intricate relation between language and the self-is deepened and further elaborated. Cor Baerveldt (2014) focuses resolutely on the in-between, advocating for a radically dialogical ontology. Although Baerveldt acknowledges the relevance of all contributions to such an ontology, he questions whether the authors are going far enough. His commentary proposes some considerations concerning the possibility of a radically dialogical ontology and connects this discussion to the genetic legacy in psychology, particularly Goethe's Lebensphilosophie ("philosophy of life"; see e.g., Goethe, 1926). The commentary by 
Lakshmi Bandlamudi (2014) equally embraces notions and arguments found in all articles. For Bandlamudi, the movements in speaking, listening, thinking, and writing make visible the ever-evolving self in linguistic transactions with ever-shifting others, whereby the language used is equally dialogic. Bandlamudi engages in a vivid dialogue with the articles, bringing in perspectives from Indian philological and philosophical traditions. In particular, Bandlamudi offers a dialogue between Sanskrit Grammarian Bhartrhari and Mikhail Bakhtin. The commentary by Judith Lysaker (2014) discusses a set of ideas presented in the articles by Lipari, Karsten, and Bertau from the perspective of a reading researcher. Lysaker is specifically interested in how an exploration of these ideas when applied to reading might illuminate reading as "an event of the self." This could lead to a more person-centered, rather than cognitive processing, view of what happens when children learn to read, when they enter literacy. To this end, Lysaker presents a case example of a dialogical picture-book reading as precursor to solitary and silent reading of written words. The final commentary is given by John Shotter (2014) who raises the subject of control that belongs to the self-contained and independent I. Emphasizing that human beings need to see themselves as essentially living within "back-and-forth relations with the others and otherness around" (p. 592) them, Shotter is principally in accordance with Lipari and Bertau. But Shotter wants to go further into performance, in this case concerning theorizing itself. In the perspective of the living relations with each other and the surroundings, Shotter advocates for a hermeneutical in contrast to a representational theorizing activity in order to understand the dialogical. Shotter has thus opened up the present issue's perspective to a meta-scientific and self-reflective level that the dialogical paradigm must, in fact, necessarily and urgently address.

I am very pleased to present this special issue as a conversation through several texts, hopefully inviting further dialogues. Of course, as is always the case, our contributions rely on texts and voices which themselves remain hidden: careful and inspiring - in the best sense, critical - peer reviews and intense dialogues. I think that these texts - never supposed to be published and for that very reason so free and serious, so fully addressedare immensely precious for any author. In this sense, we are grateful to John Cromby, Hanne De Jaegher, Bob Fecho, Ken Gergen, Vincent Hevern, Robert Innis, Clemens Knobloch, Michelle Mamberg, Paul Prior, Peter Raggatt, João Salgado, Anna Sfard, David Skidmore, Peter Smagorinsky, William Smythe, Tom Strong, Anton Yasnitsky, and Mark Zuss.

\section{Acknowledgements}

I am thankful to Michelle Mamberg, whose careful reading, pertinent questions, and comments allowed me to improve this introduction's English.

\section{Notes}

1. From the perspective of cultural-historical activity theory, Stetsenko and Arievitch (2004) review several presently influential trends that all highlight the importance of the social context for the self; one of these trends is the dialogical approaches in psychology that ground the self ontologically as constituted by relatedness, dialogism, and responsiveness, which means for Stetsenko and Arievitch (2004) in short: practical material processes are to be further explored 
in order to really acknowledge the self as profoundly social phenomenon (p. 480). I agree with the authors inasmuch as language is not consequently broached and theorized within a socio-dialogical and pragmatic, cultural-historical psychological framework-taking it only as a discursive practice among others ("language, dialogue and other discursive processes," $\mathrm{p}$. 480 ) is, indeed, not enough. I share the authors' urge to take transformative collective material practices into account, but I would not put language aside of "collective materiality" as it were; rather, I would like to emphasize the fact that symbolic language is deeply grounded in experienced, living, embodied materiality pertaining to forms of common practice (Gratier \& Bertau, 2012), and that it is as such entangled with all kinds of human activity in a highly complex way. Language is itself a practice, and I invite the readers of this issue precisely to go a step further than "discursive processes" into language activity (see also Bertau, 2011b).

2. See my contribution to this special issue, Bertau (2014b).

\section{References}

Baerveldt, C. (2014). The ontology of the "in-between" and the genetic legacy in psychology. Theory \& Psychology, 24, 542-560.

Bakhtin, M. M. (1984). Problems of Dostoevsky's poetics (C. Emerson, Ed. \& Trans.). Minneapolis: University of Minnesota Press. (Original work published 1929)

Bakhtin, M. M. (1986). Speech genres and other late essays (C. Emerson \& M. Holquist, Eds. \& V. W. McGee, Trans.). Austin: University of Texas Press.

Bandlamudi, L. (2014). On movements of language - within self, of self, about self, and between selves: Commentary on language and self. Theory \& Psychology, 24, 561-575.

Bertau, M.-C. (2011a). Anreden, Erwidern, Verstehen: Elemente einer Psycholinguistik der Alterität [Address, reply, understanding: Elements of a psycholinguistics of alterity]. Berlin, Germany: Lehmanns Media.

Bertau, M-C. (2011b). Language for the other: Constructing cultural-historical psycholinguistics. Tätigkeitstheorie: E-Journal for Activity Theoretical Research in Germany, 5, 13-44. Retrieved from http://www.ich-sciences.de/fileadmin/pdf/Ausgabe_5/Heft_5fertig.pdf

Bertau, M.-C. (2014a). On displacement. Theory \& Psychology, 24, 442-458.

Bertau, M.-C. (2014b). Exploring language as the "in-between." Theory \& Psychology, 24, 524 541.

Bertau, M.-C., Gonçalves, M. M., \& Raggatt, P. T. F. (2012). Introduction: A psychological paradigm for psychology. In M.-C. Bertau, M. M. Gonçalves, \& P. T. F. Raggatt (Eds.), Dialogic formations: Investigations into the origins of the dialogical self (pp. $\mathrm{xi}-\mathrm{xx})$. Charlotte, $\mathrm{NC}$ : Information Age.

Bühler, K. (2011). Theory of language: The representational function of language. Amsterdam, the Netherlands: John Benjamins. (Original work published 1934).

Clark, H. (1996). Using language. Cambridge, UK: Cambridge University Press.

Clot, Y. (2005). L'autoconfrontation croisée en analyse du travail: L'apport de la théorie bakhtinienne $d u$ dialogue [Crossed auto-confrontation in work analysis: The contribution of Bakhtin's theory of dialogue]. In L. Fillietaz \& J.-P. Bronckart (Eds.), L'analyse des actions et des discours en situation de travail: Concepts, méthodes et applications [The analysis of actions and discourses in work situations: Concepts, methods and applications] (pp. 37-55). Leuven, Belgium: Peeters.

De Jaegher, H., \& Di Paolo, E. (2007). Participatory sense-making. An enactive approach to social cognition. Phenomenological and Cognitive Science, 6, 485-507.

De Jaegher, H., Di Paolo, E., \& Gallagher, S. (2010). Can social interaction constitute social cognition? Trends in Cognitive Sciences, 14(10), 441-447. 
Gadamer, H.-G. (1986). Hermeneutik II: Wahrheit und Methode. Ergänzungen, Register [Hermeneutics II: Truth and method. Additions, register]. Tübingen, Germany: J. C. B. Mohr.

Gallagher, S. (2012). A philosophical epilogue on the question of autonomy. In H. J. M. Hermans \& T. Gieser (Eds.), Handbook of dialogical self theory (pp. 488-496). Cambridge, UK: Cambridge University Press.

Gergen, K. (2009). Dialogue as collaborative action. Journal für Psychologie 17(2). Retrieved from http://www.journal-fuer-psychologie.de/index.php/jfp/issue/view/24

Goethe, J. W., von (1926). Goethes Morphologische Schriften [Goethe's writings on morphology] (W. Troll, Ed.). Jena, Germany: Eugen Diederichs.

Gratier, M., \& Bertau, M.-C. (2012). Polyphony: A vivid source of self and symbol. In M.-C. Bertau, M. M. Gonçalves, \& P. T. F. Raggatt (Eds.), Dialogic formations: Investigations into the origins of the dialogical self (pp. 85-119). Charlotte, NC: Information Age.

Hermans, H. J. M., \& Gieser, T. (2012). (Eds.). Handbook of dialogical self theory. Cambridge, UK: Cambridge University Press.

Karsten, A. (2014). Writing: Movements of the self. Theory \& Psychology, 24, 479-503.

Larrain, A., \& Haye, A. (2014). A dialogical conception of concepts. Theory \& Psychology, 24, $459-478$.

Linell, P. (2009). Rethinking language, mind, and world dialogically. Charlotte, NC: Information Age.

Lipari, L. (2014). On interlistening \& the idea of dialogue. Theory \& Psychology, 24, 504-523.

Lysaker, J. (2014). Reading as a language event of the self: In conversation with Bertau, Lipari, and Karsten. Theory \& Psychology, 24, 576-591.

Merleau-Ponty, M. (1968). The visible and the invisible (C. Lefort, Ed. \& A. Lingis, Trans.). Evanston, IL: Northwestern University Press.

Schütz, A. (1967). The phenomenology of the social world. Evanston, IL: Northwestern University Press.

Shotter, J. (1993). Conversational realities: Constructing life through language. London, UK: Sage.

Shotter, J. (2014). From within the thick of it: Human beings doing being human in languaged worlds. Theory \& Psychology, 24, 592-605.

Shotter, J., \& Billig, M. (1998). A Bakhtinian psychology: From out of the head of individuals and into the dialogues between them. In M. Mayerfeld Bell \& M. Gardiner (Eds.), Bakhtin and the human sciences: No last words (pp. 13-29). London, UK: Sage.

Stetsenko, A., \& Arievitch, I. M. (2004). The self in cultural-historical activity theory: Reclaiming the unity of social and individual dimensions of human development. Theory \& Psychology, 14, 475-503. doi: 10.1177/0959354304044921

Trevarthen, C. (1999). Intersubjectivity. In R. A. Wilson \& F. C. Keil (Eds.), The MIT Encyclopedia of cognitive sciences (pp. 415-419). Cambridge, MA: The MIT Press.

Trevarthen, C., \& Aitken, K. J. (2001). Infant intersubjectivity: Research, theory, and clinical applications. Journal of Child Psychology and Psychiatry, 42(1), 1-48.

Valsiner, J. (2007). Becoming integrative in sciences: Re-building contemporary psychology through interdisciplinary and international collaboration. Integrative Psychological and Behavioral Sciences, 41, 1-5.

Vološinov, V. N. (1986). Marxism and the philosophy of language (L. Matejka \& R. Titunik, Trans.). Cambridge, MA: Harvard University Press. (Original work published 1929)

Weigand, E. (2009). Language as dialogue. Amsterdam, the Netherlands: John Benjamins.

Wittgenstein, L. (1953). Philosophical investigations. Oxford, UK: Blackwell. 


\section{Author biography}

Marie-Cécile Bertau is cultural-historical psycholinguist at Ludwig-Maximilians-Universität, Munich (Germany). Building on cultural-historical theory and dialogical self theory, her axiomatic framework addresses language activity as the source of social and psychological development, foregrounding the formative function of language for socio-psychological processes such as thinking, self construction, and consciousness (2011, Anreden, Erwidern, Verstehen, Lehmanns Media); central to these processes is "voice" as psycho-physical phenomenon. Recent contributions include a chapter on the development of the dialogical self (2012, Handbook of the Dialogical Self, Hermans \& Gieser, Eds., Cambridge University Press), and the co-edited book Dialogic Formations (2012, with Gonçalves \& Raggatt, IAP). Address: Ludwig-Maximilians-Universität München, Institute for Phonetics and Speech Processing, Schellingstrasse 3, 80799 München, Germany. Email: bertau@lmu.de. 